\title{
Dermatology: where are we coming from and where are we going to?
}

\section{Peter C. M. van de Kerkhof *}

Department of Dermatology, Radboud University Nijmegen Medical Centre, Nijmegen, Netherlands

${ }^{*}$ Correspondence: p.vandekerkhof@derma.umcn.nl

Edited by:

Matthias Barton, University of Zurich, Switzerland

Reviewed by:

Mette Søndergaard Deleuran, Aarhus University Hospital, Denmark

Keywords: skin diseases, dermatology, dermatoses, targeted treatments, diagnosis

\section{INTRODUCTION}

For centuries, skin diseases have been described according to their macromorphological appearance and classified according the morphological description. The system of grouping morphological features in skin diseases followed the same principles as defined by Carolus Linnaeus (1707-1778) in the taxonomy of plants and animals.

The major development of the morphological description of skin diseases was following extensive application of dermatopathology on skin biopsies. By integrating macro- and micromorphology, a new system for description of skin diseases had been created the primary efflorescences. The primary efflorescences constitute a set of macromorphological characteristics, which are indicative for the most important general pathological features (1). This system has served and still serves the classification of skin diseases. The primary efflorescences are the essentials in descriptions, diagnosis, and treatment of dermatoses. Dermatoses are classified from the point of view of the fundamental pathologic process involved. In other words, the classification is made according to the essential lesions.

During the last four decades important new insights in the genetics, pathophysiology, and cell biology have provided crucial information about the etiology and pathogenesis of skin diseases and have developed dermatology from a morphology driven discipline into an etiology based discipline. These observations have impacted the system of classification of skin diseases and the possibility for targeted treatments. The development of etiology based disease classification and targeted treatments have brought dermatology in better alignment with other medical disciplines such as internal medicine, rheumatology, and gastroenterology. In particular, the multidisciplinary approach in systemic diseases provides etiological concepts beyond the boundaries of the individual disciplines.

Skin diseases are easily accessible for inspection and investigation. That is why skin diseases are at the frontiers for advancement of insights in the etiology and pathogenesis of diseases and for understanding the mode of action of treatments.

A major question is whether classical dermatology in general practice can serve to the patients in the light of new developments? On one hand, there is a major challenge for teaching and continuing education. On the other hand, dermatology networks around centers of excellence are and will be of major importance in the future.

\section{DIAGNOSIS OF SKIN DISEASES GENODERMATOSES}

Genetic technology over the past decade has generated new knowledge in the association of allelic variations in several genes with specific skin diseases. As of today, the genetic bases of the majority of the more common genodermatoses are known. Our insight into the biology of skin diseases has increased accordingly.

Genetic counseling has been greatly aided by gene identification, DNA-based prenatal diagnosis in several conditions, and DNA-based preimplantation diagnosis has been used. A summary of genodermatoses associated with allelic variations in known genes is provided in the classic review by Irvine and McLean (2).
Irvine and McLean defined important gaps in our knowledge and directions for future research:

- genotype-phenotype correlation: clinical heterogeneity implies that different phenotypes may arise from one mutation; genetic heterogeneity implies that the same phenotype may arise from different mutations

- variable penetrance may cause different phenotypes

- revertant mosaicism is a well-known phenomenon, which contribute to the complexity of phenotype - genotype correlations.

Further investigations of the underlying mechanisms will give better clues to the clinical understanding of the genetic abnormalities. For the nosology of skin diseases, classical morphological description will permit adequate diagnosis in many patients. However, a new approach is possible, focused on the genetic observations in stead of clinical descriptions (3-5). For clinical practice, new technology may provide new opportunities and also ethical challenges. In particular, with respect to prenatal diagnosis and postnatal diagnosis, the knowledge about a genotype may pose questions with respect to termination of pregnancies and questions to interventions intended.

\section{INFLAMMATORY DERMATOSES}

Inflammatory dermatoses comprise a spectrum of different diseases. Based on the clinical description, different disease entities have been defined, which may be restricted to the skin or may be a systemic disease. Inflammatory diseases share or 
may have distinct pathogenetic processes, which may harbor a target for antiinflammatory treatments.

For example, a disease such as psoriasis remain in the majority of patients restricted to a few erythematosquamous plaques, without any sign of systemic inflammation and can be treated with a topical treatment (vitamin D analog and/or corticosteroid). About $1 / 3$ rd of patients with psoriasis has more widespread disease, with co-morbidities such as arthritis and metabolic syndrome. So far, the course of the disease is chronic and unpredictable.

The etiology of psoriasis is unknown. Several genes have shown to be involved (6). These genes comprise various pathogenetic processes such as IL-23 and IL 17 signaling, Interferon gamma signaling, NF-кB (nuclear factor kappa-light-chainenhancer of activated B cells) signaling, epidermal proliferation, and keratinization. The question arises to what extent psoriasis harbors different genotypes, which are reflected in different phenotypes. Indeed, it has been shown that the chronic plaque psoriasis and pustular psoriasis are different diseases, with respect to genotype and phenotype (7). Further studies are needed to understand better, the differences in clinical aspects of psoriasis in the light of different genes involved in the individual patients.

Phototherapy, methotrexate, cyclosporin, acitretin, and fumarates are the most established classical treatments for psoriasis. In case of insufficient control treatment with anti-TNF biologics (etanercept, adalimumab, or infliximab) or with the anti Il12-23 (ustekinumab). It remains an art to select the appropriate treatment in an individual patient based on relevant co-morbidities and the requirement of therapeutic strength.

Every patient has his/her own psoriasis and that is true, in particular, with respect to treatment. Current interest is on development of co-diagnostics to predict the course of the disease and responsiveness to the various treatments. Genetic markers, immune markers, and pharmacological markers are helpful.

\section{ONCOLOGY}

\section{NON-MELANOMA SKIN CANCER}

Non-melanoma skin cancer (NMSC) is the most frequent malignancies of the skin. During the last 3 decades an important increases of NMSC has been noticed, resulting from more extensive exposition of the skin to UV radiation. The diagnosis and subsequent treatment of premalignancies and malignancies belonging to NMSC are a major task for dermatologists and general practitioners. An important future possibility to facilitate rapid diagnosis is in vivo confocal microscopy (8). However, it has to be realized that the restricted in vivo penetration of the laser light is an important limitation of this method.

\section{MELANOMA}

Mutations in BRAF-oncogene are responsible for continuous growth in $60 \%$ of melanoma's (9). Other mutations are in KIT - gene in acral, mucosal, and lentigo melanoma (10). Various kinase inhibitors inhibit kinases associated with continuous growth of melanoma via individual mutations. Further studies on relevant mutations and the molecular control of growth induced by these oncogenes may lead to a target therapy of advanced melanoma.

\section{TARGETED TREATMENTS \\ GENODERMATOSES}

Therapeutic strategies according to the underlying genetic mechanisms have been developed. The easy access to the skin compared with solid internal organs, provides unique opportunities for cutaneous gene therapy; however, many technical issues have to be addressed to enable gene replacement or modification of gene expression in genetic diseases.

With ex vivo cutaneous gene therapy, a gene therapy vector is incorporated in cultured keratinocytes derived from a patient s biopsy and then grafted back onto the patient's skin using well-established technology developed for the treatment of burns and, more recently, for stable vitiligo (11). Mutant gene expression has been successfully rescued in cultured keratinocytes from a variety of recessive genodermatoses, including Recessive Dystrophic Epidermolysis Bullosa - Herlitz (RDEB-HS) (12) junctional epidermolysis bullosa, type Herlitz (JEB-H) (13), and others. The system has been used to treat successfully cells from patients with JEB-H (14) and $\mathrm{X}$-linked ichthyosis (15).

In vivo gene therapy provides direct transfer of a therapeutic gene construct into the skin of the patient. One difficulty here is getting DNA past the highly evolved barrier function of the skin.

mRNA inactivation have been developed, based on short inhibitory RNA (siRNA) technology (16). Another RNAbased approach is that of RNA transsplicing, aimed at correcting mutations in recessive or dominant conditions. This has recently been used to correct mutations in collagen XVII in vitro (17).

Gene repair oligonucleotides are small DNA-RNA hybrid molecules that can target and correct the mutation within a given gene.

\section{INFLAMMATORY DERMATOSES}

Although many patients are treated with topicals, phototherapy, and laser treatments the major innovations were not primarily in this area. Development of pathogenesis based treatments was possible by the interventions with biologics targeted at specific sites in the pathogenesis of inflammatory diseases.

A variety of classical anti-inflammatory treatments and innovative targeted treatments (biologics and small molecules) are available. In particular, in the field of psoriasis new treatments are currently developed. These applications may often be of benefit for other inflammatory diseases.

Reverting to psoriasis, so far no early biomarkers, indicative for a more active course with more widespread disease or systemic involvement are available. So far, the question whether early active intervention is needed in at least some patients is not known (18).

During the course of the disease, it is very difficult to indicate with certainty, whether a systemic treatment with a classical antipsoriatic drug (methotrexate, fumarates, cyclosporin, or retinoids) is indicated in an individual, or whether the patient has to be treated with a biologic (either anti-TNF or ustekinumab).

So far, some evidence is available that plasma through levels of biologics are important to avoid under - and overdosing $(19,20)$ Some evidence is available that TNFAIP3 gene polymorphism will be associated with better responsiveness to anti-TNF (21) and HLA-Cw6 but not LCE3B/3C deletion nor TNFAIP3 polymorphism will be associated with better responsiveness to ustekinumab (22). 
In psoriasis, new treatments in development are the biologics with anti-IL-17 action, anti IL-23, and the small molecules apremilast (anti-phosphodiesterase 4) and tofacitinib (JANUS kinase inhibitor) (23-29).

Future research is focused on understanding, which treatment has to be given to which patient and when. Biomarkers and co-diagnostics to help guiding future treatment in the individual patients are of crucial value to provide optimal care.

With the development of small molecules, new innovative topical treatments will become reality in the near future. Pathogenesis based treatments will than innovate the management of frequently occurring more mild expressions of inflammatory skin diseases.

\section{ONCOLOGY}

\section{NON-MELANOMA SKIN CANCER}

In addition to the traditional treatments such as surgery, cryotherapy and radiotherapy, and photo dynamic therapy, stimulation of cytotoxic immunity by imiquimod is an important advance (30). In future, further immunostimulatory treatments may provide important opportunities for targeted treatment of NMSC.

\section{MELANOMA}

Targeted therapy with inhibitors of the BRAF and MKE proteins is well-established for those patients with BRAF-mutant melanoma (31). However, following a clinical response, resistance develops in the tumors treated with these agents.

Another new approach is immunotherapy with antibodies, modulating the interaction between dendritic cells and T lymphocytes by blocking CTLA-4 and PD-1 (31-33). This results in augmented cell immunity and in a durable clinical response in melanoma patients.

\section{FUTURE PROSPECTS}

Further studies beyond the boundaries of clinical classification may help to define stratification, which is relevant to the course of a disease and with respect to responsiveness to individual treatments. Indeed, personalized medicine will provide important future opportunities. This impacts our research, which so far often was focused on "group analyses," into approach to focus on individual genotypical and phenotypical identifications.
For the society, individualized personalized care will be more cost effective as unnecessary interventions can be restricted to focused individualized care.

\section{REFERENCES}

1. Darier J. Precis de Dermatologie. 2 ed. Paris: Masson (1918).

2. Irvine AD, McLean WH. The molecular genetics of geodermatoses: progress todate and future directions. Br J Dermatol (2003) 148:1-13. doi:10.1046/ j.1365-2133.2003.05220.x

3. Moss C. A new way to classify genetic skin disease. J Invest Dermatol (2009) 129:2543-5. doi:10.1038/ jid.2009.292

4. Betz RC, Cabral RM, Christiano AM, Sprecher E. Unveiling the roots of monogenic genodermatoses: genotrichoses as a paradigm. J Invest Dermatol (2012) 132:906-14. doi:10.1038/jid.2011.408

5. Lemke JR, Kernland-Lang K, Hörtnagel K, Itin P. Monogenic human skin disorders. Dermatology (2014). doi:10.1159/000362200

6. Van de Kerkhof PCM, Nestle FO. Psoriasis in Dermatology. Third ed. New York, NY: Mosby, Elsevier (2011). p. 135-56.

7. Marrakchi S, Guigue P, Renshaw BR, Puel A, Pei XY, Fraitag S, et al. Interleukin-36-receptor antagonist deficiency and generalized pustular psoriasis. N Engl J Med (2011) 365:620-8. doi:10.1056/ NEJMoa1013068

8. Garcia-Uribe A, Zou J, Duvic M, Cho-Vega JH, Prieto VG, Wang LV. In vivo diagnosis of melanoma and nonmelanoma skin cancer using oblique incidence diffuse reflectance spectrometry. Cancer Res (2012) 72:2738-45. doi:10.1158/0008-5472.CAN11-4027

9. Davies H, Bignell GR, Cox C, Stephens P, Edkins $\mathrm{S}$, Clegg S, et al. Mutations of the BRAF gene in human cancer. Nature (2002) 417(6892):949-54. doi:10.1038/nature00766

10. Hodi FS, Corless CL, Giobbie-Hurder A, Fletcher JA, Zhu M, Marino-Enriquez A, et al. Imatinib for melanomas harboring mutationally activated or amplified KIT arising on mucosal, acral, and chronically sun-damaged skin. J Clin Oncol (2013) 31:3182-90. doi:10.1200/JCO.2012.47. 7836

11. Guerra L, Capurro S, Melchi F, Primavera G, Bondanza S, Cancedda R, et al. Treatment of "stable" vitiligo by timed surgery and transplantation of cultured epidermal autografts. Arch Dermatol (2000) 136:1380-9.

12. Compton SH, Mecklenbeck S, Mejía JE, Hart SL, Rice M, Cervini R, et al. Stable integration of large ( $>100 \mathrm{~kb}$ ) PAC constructs in HaCaT keratinocytes using an integrin-targeting peptide delivery system. Gene Ther (2000) 7:1600-5. doi:10.1038/sj. gt. 3301280

13. Vailly J, Gagnoux-Palacios L, Dell'Ambra E, Roméro C, Pinola M, Zambruno G, et al. Corrective gene transfer of keratinocytes from patients with junctional epidermolysis bullosa restores assembly of hemidesmosomes in reconstructed epithelia. Gene Ther (1998) 5:1322-32. doi:10. 1038/sj.gt.3300730

14. Robbins PB, Lin Q, Goodnough JB, Tian H, Chen $\mathrm{X}$, Khavari PA. In vivo restoration of laminin 5 beta 3 expression and function in junctional epidermolysis bullosa. Proc Natl Acad Sci U S A (2001) 98:5193-8. doi:10.1073/pnas.091484998

15. Freiberg RA, Choate KA, Deng H, Alperin ES, Shapiro LJ, Khavari PA. A model of corrective gene transfer in X-linked ichthyosis. Hum Mol Genet (1997) 6:927-33. doi:10.1093/hmg/6.6.927

16. Elbashir SM, Martinez J, Patkaniowska A, Lendeckel W, Tuschl T. Functional anatomy of siRNAs for mediating efficient RNAi in Drosophila melanogaster embryo lysate. EMBO J (2001) 20:6877-88. doi:10.1093/emboj/20.23.6877

17. Dallinger G, Puttaraju M, Mitchell LG, Yancey KB, Hintner H, Bauer JW. Collagen 17Al gene correction using spliceosome mediated RNA transsplicing (SMaRT) technology. J Invest Dermatol (2000) 115:332. doi:10.1046/j.1523-1747.2000. 115002332.x

18. Girolomoni G, Griffiths CE, Krueger J, Nestle FO, Nicolas JF, Prinz JC, et al. Early intervention in psoriasis and immune-mediated inflammatory diseases: a hypothesis paper. J Dermatolog Treat (2014):19.

19. Mahil SK, Arkir Z, Richards G, Lewis CM, Barker JN, Smith CH. Predicting treatment response in psoriasis using serum levels of adalimumab and etanercept: a single centre, cohort study. Br J Dermatol (2013) 169:306-13. doi:10. 1111/bjd.12511

20. van Kuijk AW, de Groot M, Stapel SO, Dijkmans BA, Wolbink GJ, Tak PP. Relationship between the clinical response to adalimumab treatment and serum levels of adalimumab and anti-adalimumab antibodies in patients with psoriatic arthritis. Ann Rheum Dis (2010) 69:624-5. doi:10.1136/ard.2009. 108787

21. Tejasvi T, Stuart PE, Chandran V, Voorhees JJ, Gladman DD, Rahman P, et al. TNFAIP3 gene polymorphisms are associated with response to TNF blockade in psoriasis. J Invest Dermatol (2012) 132:593-600. doi:10.1038/jid.2011.376

22. Talamonti M, Botti E, Galluzzo M, Teoli M, Spallone $\mathrm{G}$, Bavetta $\mathrm{M}$, et al. Pharmacogenetics of psoriasis: HLA-Cw6 but not LCE3B/3C deletion nor TNFAIP3 polymorphism predisposes to clinical response to interleukin 12/23 blocker ustekinumab. Br J Dermatol (2013) 169:458-63. doi:10. 1111/bjd.12331

23. Langley RG, Elewski BE, Lebwohl M, et al. Secukinumab in plaque psoriasis - results of two phase 3 trials. the ERASURE and FIXTURE study groups. N Engl J Med (2014)

24. Leonardi CL, Gordon KB. New and emerging therapies in psoriasis. Semin Cutan Med Surg (2014) 33(2 Suppl 2):S37-41. doi:10.12788/j.sder. 0066

25. Leonardi C, Matheson R, Zachariae C, Cameron G, Li L, Edson-Heredia E, et al. Anti-interleukin17 monoclonal antibody ixekizumab in chronic plaque psoriasis. N Engl J Med (2012) 366:1190-9. doi:10.1056/NEJMoa1109997

26. Papp KA, Leonardi C, Menter A, Ortonne JP, Krueger JG, Kricorian G, et al. Brodalumab, an anti-interleukin-17-receptor antibody for psoriasis. N Engl J Med (2012) 366:1181-9. doi:10.1056/ NEJMoal109017

27. Strober B, Buonanno M, Clark JD, Kawabata T, Tan $\mathrm{H}$, Wolk R, et al. Effect of tofacitinib, a Janus kinase inhibitor, on haematological parameters during 12 
weeks of psoriasis treatment. Br J Dermatol (2013) 169:992-9. doi:10.1111/bjd.12517

28. Papp KA, Kaufmann R, Thaçi D, Hu C, Sutherland D, Rohane P. Efficacy and safety of apremilast in subjects with moderate to severe plaque psoriasis: results from a phase II, multicenter, randomized, double-blind, placebo-controlled, parallelgroup, dose-comparison study. J Eur Acad Dermatol Venereol (2013) 27(3):e376-83. doi:10.1111/j. 1468-3083.2012.04716.x

29. Sofen H, Smith S, Matheson RT, Leonardi CL, Calderon C, Brodmerkel C, et al. Guselkumab (an IL-23-specific mAb) demonstrates clinical and molecular response in patients with moderateto-severe psoriasis. J Allergy Clin Immunol (2014) 133:1032-40. doi:10.1016/j.jaci.2014.01. 025

30. Micali G, Lacarrubba F, Bhatt K, Nasca MR. Medical approaches to non-melanoma skin cancer.
Expert Rev Anticancer Ther (2013) 13:1409-21. doi:10.1586/14737140.2013.856759

31. Flaherti KT, Hodi FS, Fisher DE. From genes to drugs: targeted strategies for melanoma. Nat Rev Cancer (2012) 12:349-61. doi:10.1038/ nrc3218

32. Topalian SL, Hodi FS, Brahmer JR, Gettinger SN, Smith DC, McDermott DF, et al. Safety, activity, and immune correlates of anti-PD-1 antibody in cancer. N Engl J Med (2012) 366:2443-54. doi:10.1056/NEJMoa1200690

33. Ott PA, Hodi FS, Robert C. CTLA-4 and PD-1/PDL1 blockade: new immunotherapeutic modalities with durable clinical benefit in melanoma patients. Clin Cancer Res (2013) 19:5300-9. doi:10.1158/ 1078-0432.CCR-13-0143

Conflict of Interest Statement: The author declares that the research was conducted in the absence of any commercial or financial relationships that could be construed as a potential conflict of interest.

Received: 28 July 2014; accepted: 07 October 2014; published online: 24 October 2014.

Citation: van de Kerkhof PCM (2014) Dermatology: where are we coming from and where are we going to? Front. Med. 1:40. doi: 10.3389/fmed.2014.00040

This article was submitted to Dermatology, a section of the journal Frontiers in Medicine.

Copyright (c) 2014 van de Kerkhof. This is an open-access article distributed under the terms of the Creative Commons Attribution License (CC BY). The use, distribution or reproduction in other forums is permitted, provided the original author(s) or licensor are credited and that the original publication in this journal is cited, in accordance with accepted academic practice. No use, distribution or reproduction is permitted which does not comply with these terms. 